\title{
Preparation and Study of colloidal CdO nanoparticles by laser ablation in polyvinylpyrrolidone
}

\author{
Ibrahim R. Agool ${ }^{1, a}$, Ahmed N. Abd ${ }^{1, b}$, Mohammed O. Dawood ${ }^{1, c}$ \\ ${ }^{1}$ Physics Department, Faculty of Science, University of Al- Mustansiriyah, Baghdad, Iraq \\ Corresponding author, E-mail: ahmed_naji_abd@yahoo.com \\ a Dr.agoolir@yahoo.com, ${ }^{b}$ ahmed_naji_abd@yahoo.com, ${ }^{\text {c }}$ mohammedodda@yahoo.com
}

Keywords: Nanoparticles, laser ablation , XRD , AFM , Transparent conducting oxides

\begin{abstract}
Nanoparticles $\mathrm{NP}_{\mathrm{S}}$ of cadmium oxide $\mathrm{CdO}$ were generated by laser ablation of a solid target (cadmium) in polyvinylpyrrolidone (PVP) solution. CdO colloidal nanoparticles have been synthesized by laser ablation Nd:YAG $(1064 \mathrm{~nm}, 100$ pulses, pulse energy= $400 \mathrm{~mJ})$ when the solid target $\mathrm{CdO}$ was immersed in PVP. Structure, topography and optical properties of the $\mathrm{CdO}$ nanoparticles $\mathrm{NP}_{\mathrm{S}}$ have been studied using X-ray diffraction (XRD), atomic force microscope (AFM) and the UV-Vis absorption respectively.
\end{abstract}

\section{Introduction}

Particles with dimensions in the nanometer range made out of II-VI semiconductors are important material for optoelectronic applications [1]. The vast majority of established high -yield method to synthesize nearly mono disperse II-VI semiconductors quantum dot distributions is based on chemical approaches. The most widely used synthetic routes to synthesize $\mathrm{CdO}$ and $\mathrm{CdTe}$ nanostructures use aqueous solutions facing various functional groups (e.g polar and unpolar thiols, amines and others) are employed to stabilize the particles[2]. Purely physical production methods which allow the synthesis of uncapped particles were limited to mechanical ball milling processes [3-5] and laser ablation in liquids which used to generate noble metal nanoparticles in suspension is known since 1993 [6-9] and was also applied to several non-metallic systems [9,10]. Also semiconductors nanoparticles were fabricated by other methods, such as deposition on different substrates by pulsed electron deposits technique [11], pulsed laser deposition [12] or pulsed laser ablation in argon gas atmosphere and methanol vapors [13] as well as by laser ablation in liquid environments (usually using long pulse laser sources at high fluence) [14].

The aim of this work focused on the preparation of CdO nanoparticle by PLAL technique in order to study their structural, morphological and optical properties.

\section{Experimental details}

Figure 1 shows the experimental setup for laser ablation of cadmium Cd solid target immersed in polyvinylpyrrolidone, which includes the laser source Nd:YAG laser system type HUAFEI, $\lambda=1064 \mathrm{~nm}$ wavelength with maximum energy per pulse of $400 \mathrm{~mJ}$, pulse width of $9 \mathrm{~ns}$, repetition rate of $(1 \mathrm{~Hz})$ and beam diameter of $2.3 \mathrm{~mm}$. The laser is applied to a lens of $12 \mathrm{~cm}$ focal length to achieve high laser fluence. $\mathrm{Cd}$ pure pellet (diameter $=5 \mathrm{~mm}$ ) was used in this work as a target material for the preparation of $\mathrm{CdO}$ nanoparticles. The ablation process was typically done for (1 $\mathrm{min})$ at room temperature. The target and a glass container are rotated by a base rotator during the process. 


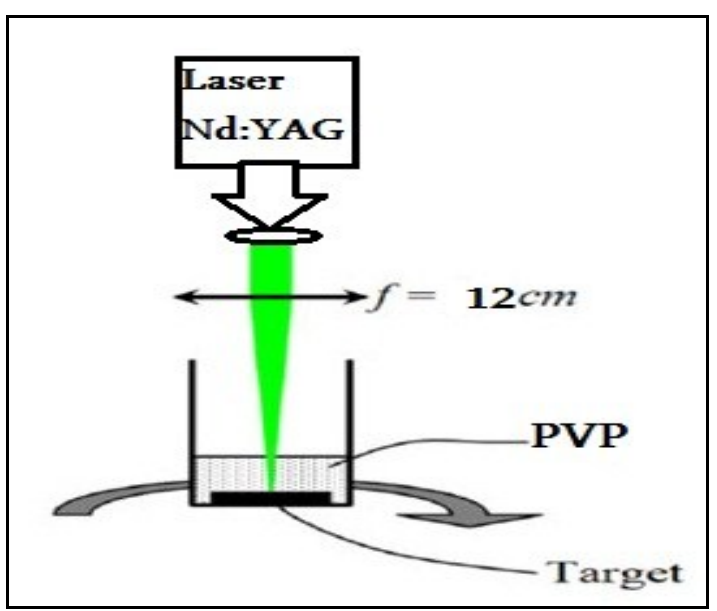

Fig.1:Experimental set-up for preparation by laser ablation.

X-ray diffractometer (shimadzu - XRD 6000, Shimadzu Company / Japan). with CuK $\alpha$ radiation $(\lambda=1.5406 \AA)$ in the range of $20^{\circ}-60^{\circ}(2 \theta)$ at a scanning rate of $0.05^{\circ} \mathrm{min}$. Scanning electron microscope SEM (T-scan Vega III Czech) and transmission electron microscopy TEM (type CM10 pw6020, Philips Germany) were employed to study the structure of nanoparticles, elemental analysis and mapping of the synthesized nanoparticles. Atomic force microscope AFM (AA 3000 scanning probe microscope) was employed to study the morphology of nanoparticles. The absorption of the colloidal nanoparticles solution was measured by using UV-Vis double beam spectrophotometer (CECIL, C. 7200, France). FT-IR spectra were recorded by Perkin Elmer Spectrometer. Photoluminescence spectra were recorded using Shimadzu-5301 spectrophotometer.

\section{Results and discussion}

PVP has been applied as a solvent. During laser ablation in PVP, the color of the solvent has been changed to yellow, we expect the formation of $\mathrm{CdO}$ particles. The efficiency of particle formation is affected by properties of solution, as shown in Fig. 2.

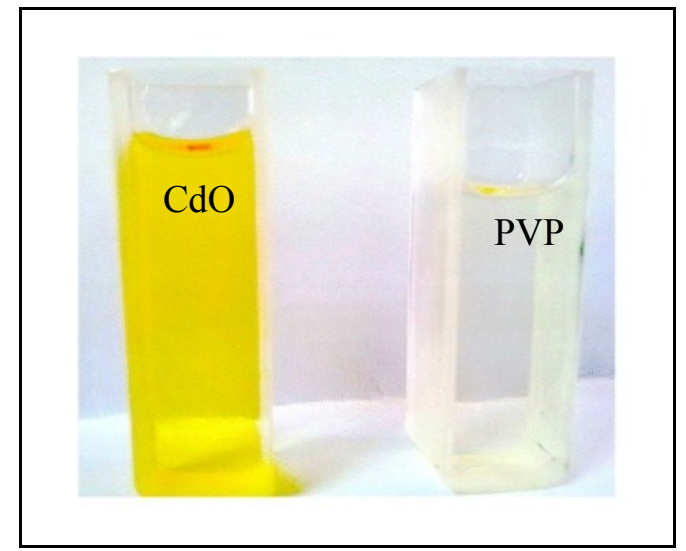

Fig.2: Photograph of colloidal CdO NPS in PVP solution.

Fig. 3 illustrate the UV-Vis spectra of $\mathrm{PVP}$ solution containing $\mathrm{CdO} \mathrm{NP}_{\mathrm{S}}$ prepared by laser ablation in liquid technique. The spectra shows plasmon resonance peak due to quantum size effect at UV range (300-360) $\mathrm{nm}$, also the transmittance and absorption curves were subdivided into two regions at the visible region. The absorption curve decreases sharply from $360 \mathrm{~nm}$ up to 540 $\mathrm{nm}$ and after this wavelength tends to saturate. So the $\mathrm{CdO} \mathrm{NP}_{\mathrm{S}}$ have a good transmittance in the visible range, which can be used in solar cell and a smart window . 

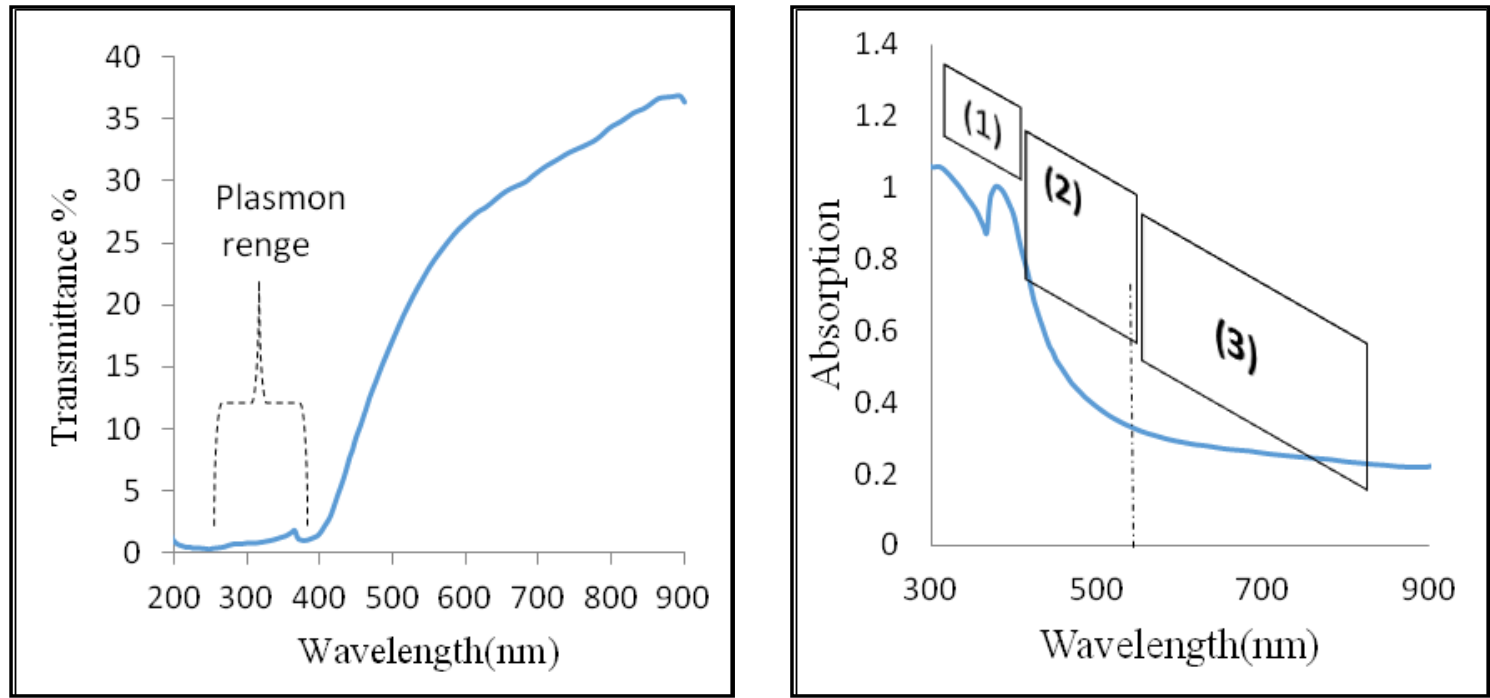

Fig.3: UV-Vis transmittance (left) and absorption(right) spectra of nanoparticles colloid fabricated at wavelength $\mathrm{CdO}$ ablated with $400 \mathrm{~mJ}$ at $1064 \mathrm{~nm}$.

Fig. 4 shows the variation of $(\alpha h v)^{2}$ verses hv for direct band gap which have been determined by the extrapolation of linear portion versus the photon energy axis. It can be seen that the value of the energy gap is about $2.8 \mathrm{eV}$. This optical phenomenon indicates that these nanoparticles show the quantum size effect $[15,16]$.

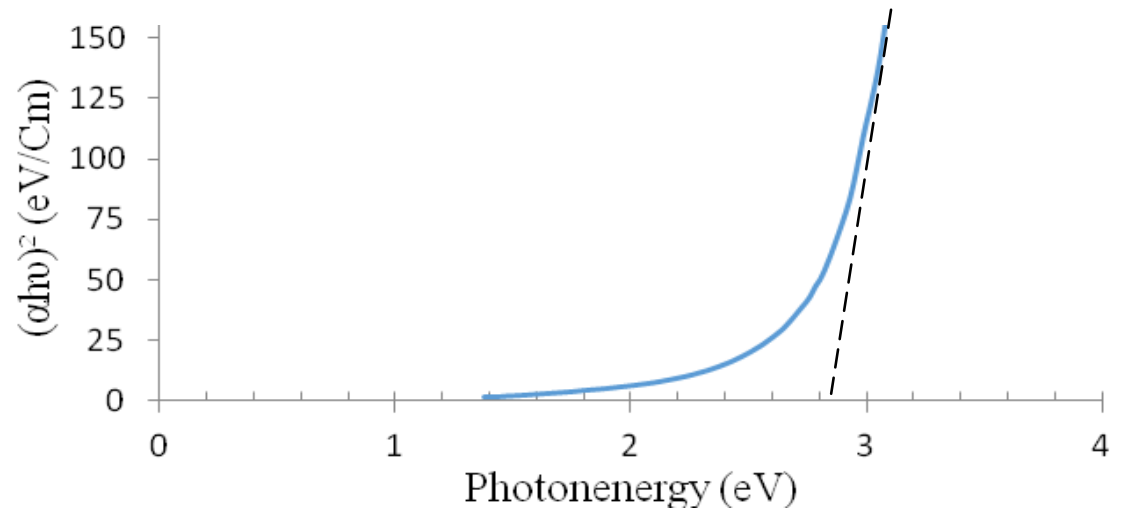

Fig.4: $(\alpha h v)^{2}$ versus photon energy plot for laser of $1064 \mathrm{~nm}$ in PVP.

The XRD patterns of the $\mathrm{CdO}$ nanostructure showed diffraction peaks absorbed at $2 \theta$ values (Fig. 5). The prominent peaks were used to calculate the crystallite size via the Scherrer equation expressed as follows [17]:

$D=\frac{0.94 \lambda}{\beta \cos (\theta)}$

Where $\lambda$ is the wavelength $(\lambda=0.1542 \mathrm{~nm})(\mathrm{CuK} \alpha), \beta$ is the full width at half maximum (FWHM) of the line, and $\theta$ is the diffraction angle. The crystallite size estimated using the relative intensity peak (002) for $\mathrm{Cd}$ and (111) for $\mathrm{CdO}$ nanoparticles and was found to be around $69 \mathrm{~nm}$ and $47 \mathrm{~nm}$ respectively, as shown in Table 1. Increase in sharpness of XRD peaks indicates that particles are in crystalline nature. The (200), reflections are clearly seen and closely match the reference patterns for CdO (Joint Committee for Powder Diffraction Studies (JCPDS) File No. 05-0640). The sharp XRD peaks indicate that the particles were of polycrystalline structure, and that the nanostructure grew with a random orientation [18]. 
The microstrain $(\gamma)$ and the dislocation density $(\sigma)$ can be calculated by using the following relations [18], see Table (1):

$$
\begin{aligned}
& \gamma=\frac{\beta \cos \theta}{4} \\
& \sigma=\frac{1}{D^{2}}
\end{aligned}
$$

\begin{tabular}{|c|c|c|c|c|c|c|}
\hline $\begin{array}{c}2 \theta \\
(\operatorname{deg})\end{array}$ & $\begin{array}{c}\text { FWHM } \\
\text { (deg) }\end{array}$ & $\begin{array}{c}d \\
(A)\end{array}$ & $\begin{array}{l}\text { (hlk) } \\
\text { Planes }\end{array}$ & $\begin{array}{c}\mathrm{D} \\
(\mathbf{n m})\end{array}$ & $\begin{array}{c}\sigma \times 10^{14} \\
\text { lines } / \mathbf{m}^{2}\end{array}$ & $\begin{array}{c}\gamma \times 10^{-4} \\
\operatorname{lines}^{2} / \mathrm{m}^{4}\end{array}$ \\
\hline 29.84 & 0.11 & 2.99 & Cd (002) & 68.84 & 02.10 & 05.03 \\
\hline 44.28 & 0.301 & 2.04 & $\mathrm{CdO}(200)$ & 47.01 & 13.70 & 12.82 \\
\hline
\end{tabular}

Table 1: Summery of X-ray characterization

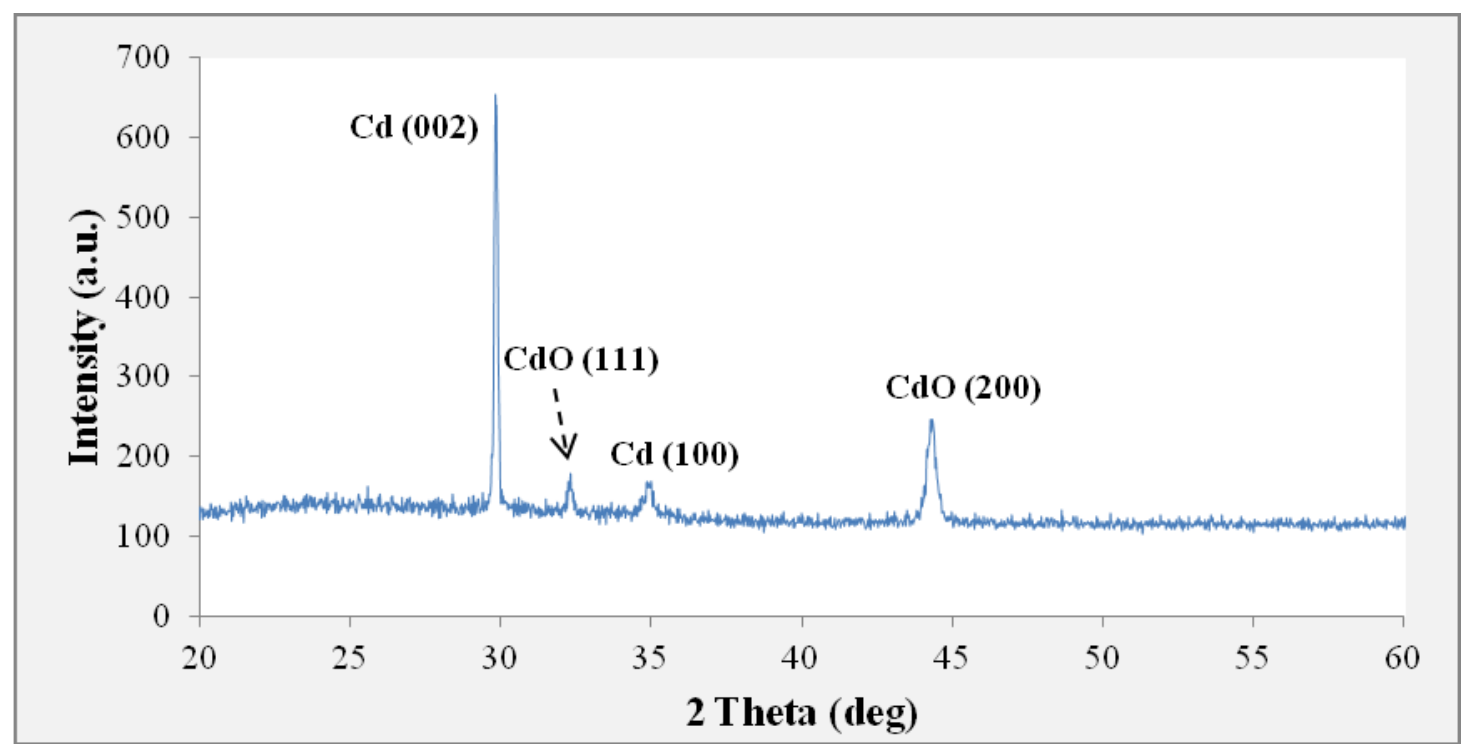

Fig. 5: XRD pattern of CdO thin film

Fig. 6 shows the 3D AFM image of the synthesized $\mathrm{CdO}$ thin film deposited on glass substrate by drop casing method. The surface of the thin film have a vertically closely packed ball -shaped, homogenous and a good roughness grains of $\mathrm{CdO}$ nanostructure within scanning area $(2 \times 2) \mu \mathrm{m}$. Using special software (4.62 imager), the estimated of average grain was around $88 \mathrm{~nm}$.

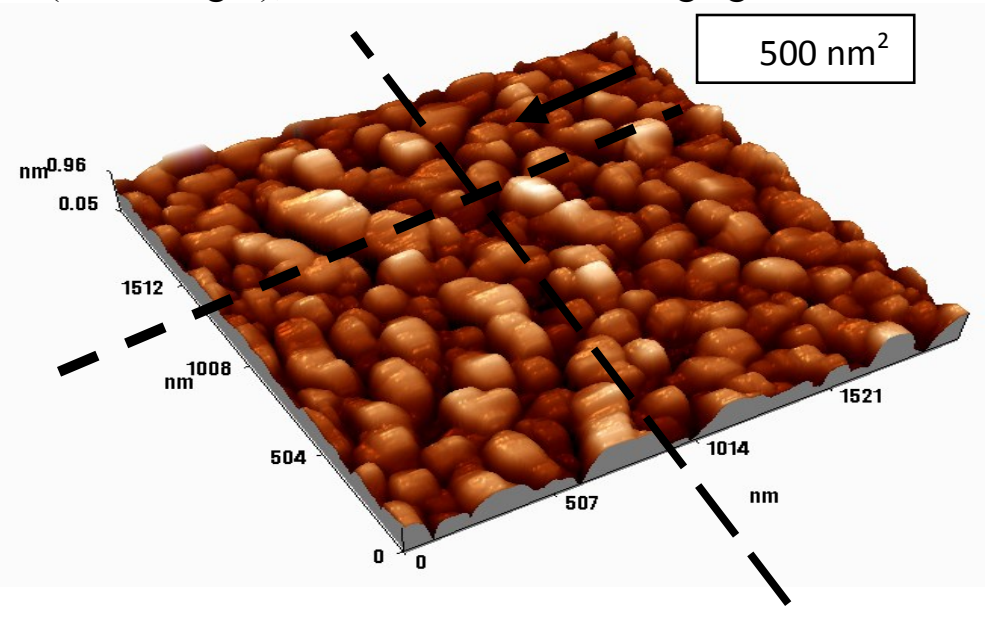

Fig. 6: 3DAFM image of synthesized CdO nanoparticles

It is clear from Fig. 7 (SEM image), that the prepared $\mathrm{CdO}$ nanoparticles have regular spherical shape and uniform size, with an average size around $52 \mathrm{~nm}$ and one can see some coalesced nanoparticles with a size of about $100 \mathrm{~nm}$. 


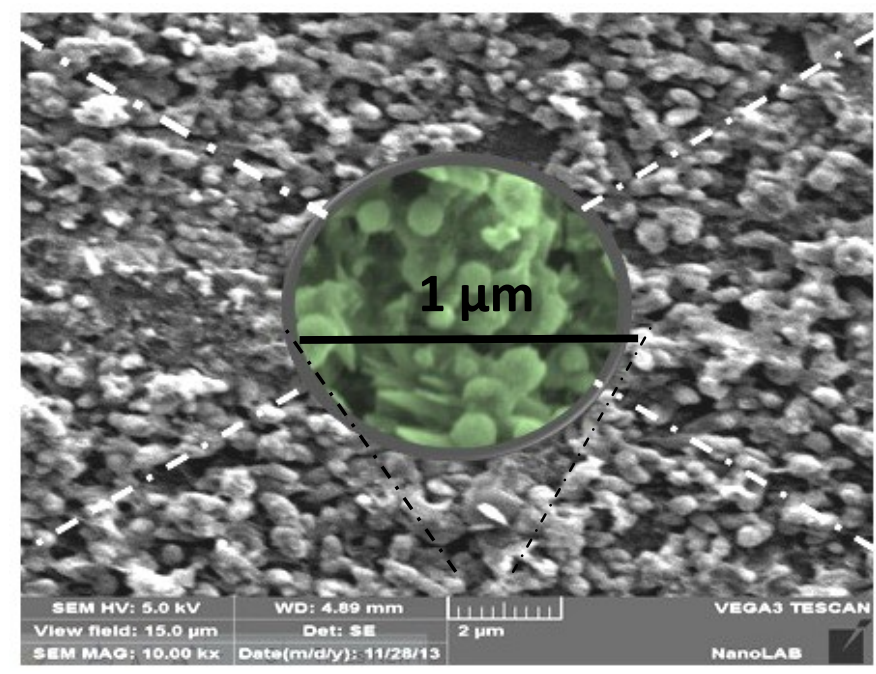

Fig. 7: 3D SEM image of synthesized CdO nanoparticles

Also, the TEM image of the CdO nanoparticles corresponding to the same sample of XRD pattern in Figure 5 and SEM in Fig.7, the particle size distribution was shown in Fig. 8. From TEM, the average particle size appears to be around $50 \mathrm{~nm}$. These particles are single crystalline as revealed by the high resolution electron microscope image. The particles are spherical or elliptical in shape.

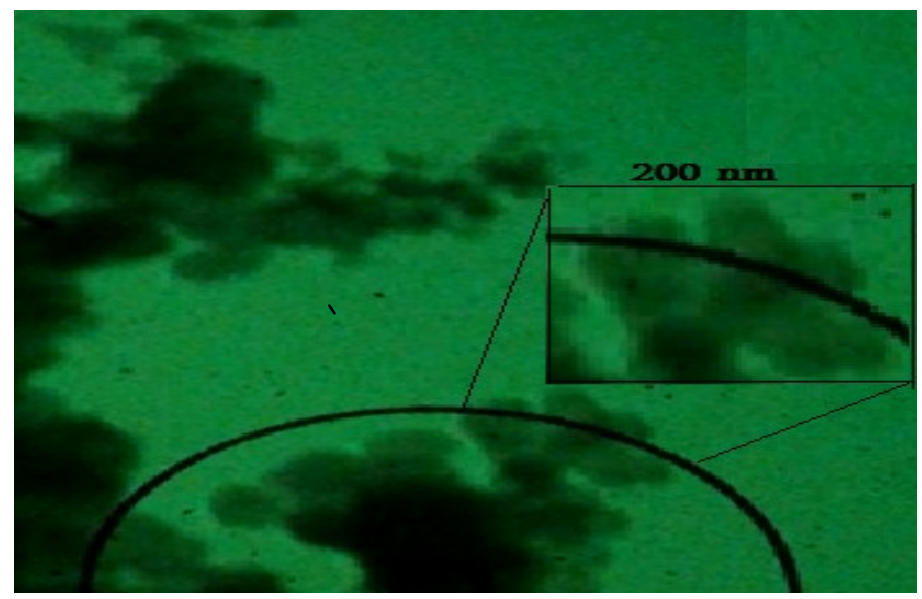

Fig. 8: TEM image of synthesized CdO nanoparticles

In Fig. 9 the peak at $1270 \mathrm{~cm}^{-1}$ and comparatively two small peaks confirm the presence of cadmium and oxygen in the sample. In the FTIR spectrum the strong absorption in the range of 1270 to $1641 \mathrm{~cm}^{-1}$ and the other couple of peaks in the range of 553 and $666 \mathrm{~cm}^{-1}$. The week absorption at 1641 is also found in the FTIR spectrum. The above cadmium reacting with oxygen in the air during the time of preparing CdO NPs. From the FTIR spectrum, it is conclude that $\mathrm{t}$ he presence of cadmium and oxygen is in the range of 1641 to $1270 \mathrm{~cm}^{-1}$ which is in good agreement with reference [19]. 


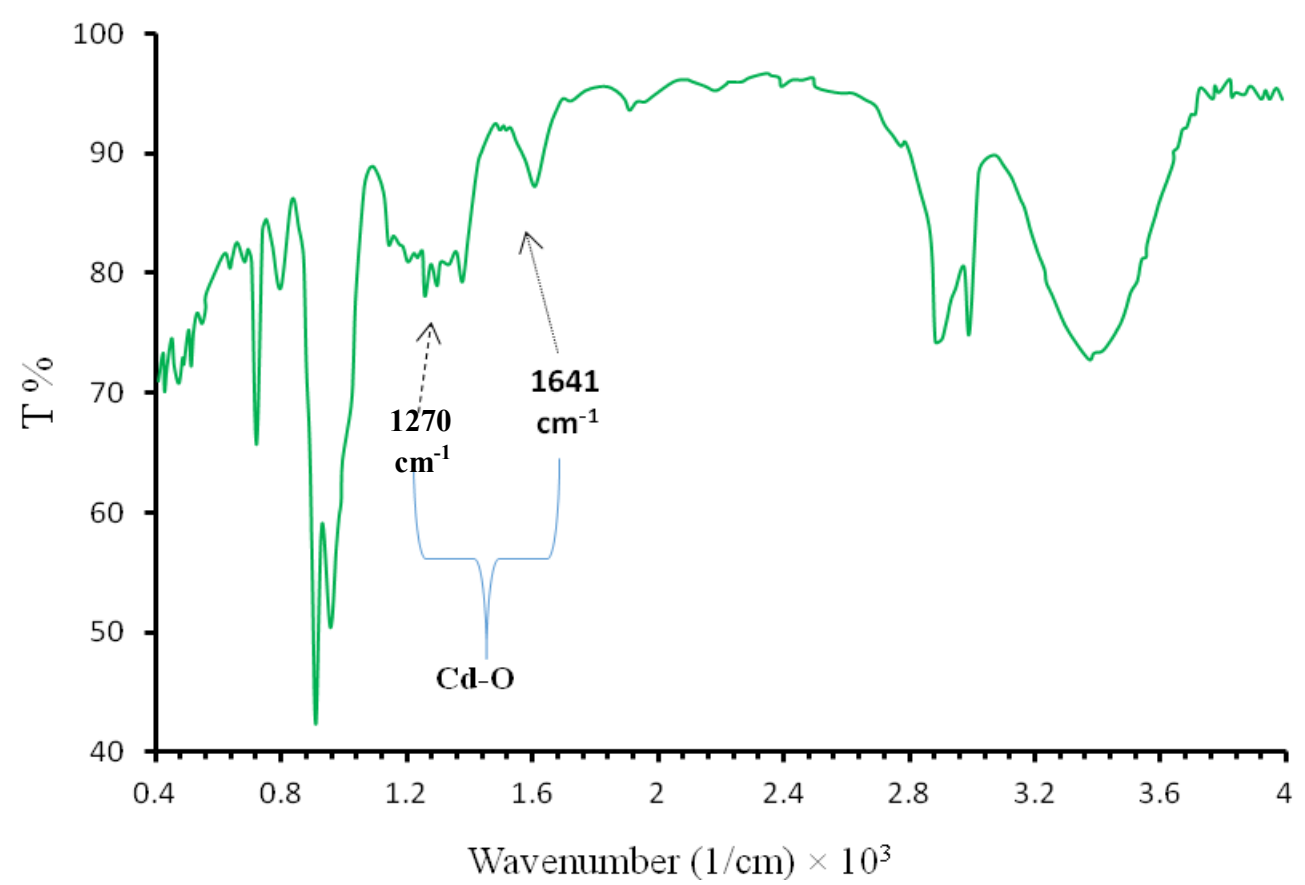

Fig. 9: Shows the Transmittance for CdO Nanoparticles.

\section{Conclusion}

The fabrication of $\mathrm{CdO} \mathrm{NP}_{\mathrm{S}}$ in PVP by laser ablation in liquid method was successfully made by this work. $\mathrm{CdO} \mathrm{NP}_{\mathrm{s}}$ have been produced by laser ablation in PVP at $(400 \mathrm{~mJ})$ laser energy, 100 pulse and $1064 \mathrm{~nm}$ wavelength. From the AFM, SEM and TEM analysis it has been found that the average grain size of $\mathrm{CdO}$ hasn't exceeded $88 \mathrm{~nm}$. Advantage of this method is convenient for synthesis of $\mathrm{CdO}$ nanoparticles in normal laboratory conditions and low cost.

\section{References}

[1] N.G. Semaltianos, S. Logothetidis, W.Perrie, S.Romani, R.J.Potter, Appl. Phys., II-VI semiconductor nanoparticles synthesized by laser ablation, A94 (2009) 641-647. URL: http://link.springer.com/article/10.1007/s00339-008-4854-y\#/page-1

[2] A. Albert. Ruth, A. John Young, Physicochem. Eng. Aspects, 279 (2006) 21 -127. URL: http://iopscience.iop.org/article/10.1088/1367- 2630/ 6/ 1/032 /meta; jsessionid = 5B39B6 5A320F29C69090FAF481A53C0E.c3.iopscience.cld.iop.org.

[3] G.L.Tan, U.Hommerich, D.Temple, N.Q.Wu, J.G, Zheng, G.Loutts, Scripla Mater., 48 (2003) 1469-1474. URL: http://www2.statler.wvu.edu/ wu/publications.htm.

[4] A.Urbieta, P.Femandez, J.Piqueras, J. Appl. Phys., 96 (2004) 2210-2213. URL: https://www.researchgate.net/publication/234863056_Study_of_structure_and_luminescence_of_C dSe_Nanocrystals_obtained_by_ball_milling

[5] G.L.Tan, Q.Yang, U.Hommerich, J.T.Sec, D.Temple, Opt.Mater., 27 (2004) 579-584. URL: www.iasj.net/iasj?func $=$ fulltext\&aId=90480.PDF

[6] A.Fojtik, A.Henglein, Ber.Bunsen- Ges. Phys. Chem., 97(1993) 252-254. URL: https://books.google.com/books?isbn=1614990204

[7] J.Neddersen, G.Chumanov, T.M. Cotton, Appl. Spectrose., 47 (1993) 1959 -1964. URL: https://books.google.com/books?isbn=9814241520 
[8] Y.P.Lee, Y.H.Liu, C.S.Yeh, Phys. Chem., 1(1999) 4681-4686.URL: www.ncku.edu.tw/ c.

[9] S. R. J. Pearce, S. J. Henley, F. Claeyssens, P.W.May, K.R.Hallam , J.A.Smith, K.N.Rosser, Dimond Rel. Mater, 13(2004) 661-665. URL: www. tlchm. bris.ac.uk/pt/diamond/pdf/drm13661.pdf

[10] K. V. Anikin, N. N. Melnik, A. V. Simakin, G.A.Shafeev, V.V.Voronov, A.G.Vitukhnovsky, Chem. Phys. Lett.,366 (2002) 357-360. URL:

Www. sciencedirect.com/science/journal/00092614/366/3-4

[11] E.Jackson, R.AgeJr, A.Steigerwald, A.Ueada, D.Coffey, L.Al-Lard, Z.Pan, W.E.Collins, R.Mu, Phys. Status Solidi, C3 (2006) 3582. URL: www.iasj.net/iasj?func=fulltext\&aId=90480

[12] D.H.Lowndes, C.M.Rouleau, T. G. Thundat, G. Duscher, E. A. Kenik, S. J. Pennycook, J. Mater. Res.,14(1999) 359.URL: https://books.google.com/books?isbn=1118114051

[13] T. Koyama, S.Ohtsuka, H.Nagata, S.Tanaka, J. Cryst. Growth, 117(1992) 156. URL: https://books.google.com/books?isbn=0444596321

[14] A.A.Ruth, J.A.Young, Colloids surf. A Physicochem, Eng. Asp., 279 (2006) 121. URL: www.iasj.net/iasj?func $=$ fulltext\&aId $=90480$

[15] X.R. Ye, C. Daraio, C. Wang, and J.B. Talbot, J. Nanoscience and Nanotechnology, 6 (2006) 852.URL: www.ncbi.nlm.nih.gov/.../1... National Center for Biotechnology Information

[16]. Z. Guo-hua, L. Ming-fang, and L. Ming-Li CEJC, 5 (2007) 1114. URL: www. degruyter. com/.../\$002fj\$002fchem.2007.5.issue-4...

[17] N. Ahmed Abd, A. Raid Ismail and F. Nadir Habubi," Preparation of colloidal cadmium selenide nanoparticles by pulsed laser ablation in methanol and toluene", journal of Materials Science: Materials in Electronics, 25(2014) .URL:

https://www.infona.pl/resource/bwmeta1.element.springer-6c04620f-01a4-308b-8f16-e0eecb0c0ebe.

[18] N. Ahmed Abd," Improved photoresponse of porous silicon photodetectors by embedding CdS nanoparticles", World Scientific News (WSN),13(2015)49 -32 . URL:

www.worldscientificnews.com/wp.../2015/07/WSN-19-2015-32-49.pdf

[19] A.S. Aldwayyan, F.M. Al-Jekhedab, M. Al-Noaimi, Synthesis and Characterization of CdO Nanoparticles Starting from Organometalic Dmphen-CdI complex, Int. J. Electrochem. Sci., 8 (2013) 10506 - 10514. URL: www. electrochemsci. org/papers/ vol8/ 80810506.pdf 